\title{
ULTRA-HIGH INTENSITY REDEVELOPMENT OF THE CORE AREA OF JAPANESE RAIL TRANSIT HUB STATION
}

\author{
CHENG-HAO YANG ${ }^{1,2}$ \& MIN-FENG YAO ${ }^{1,2^{*}}$ \\ ${ }^{1}$ School of Architecture, Huaqiao University, Xiamen, China. \\ ${ }^{2}$ Key Laboratory of Ecological Environment of Southeast Fujian Province, China.
}

\begin{abstract}
Japanese rail transit hub station has gradually changed from being high-intensity to ultra-high intensity with the guidance from the urban regeneration policy. This change aims to promote compact urban construction and optimize public transportation system for sustainable urban development. Along with demand for city expansion and city intensification, land utilization around hub stations gradually change from incremental development mode to redevelopment mode that tends to stock. This study summarizes the implementation of typical ultra-high-intensity redevelopment projects, which are classified into three categories. This study also provides a comparative study of the design methods and strategies of these cases from the perspective of developing intensity, functional layout, pedestrian system, and landscape space. Finally, this study provides relevant references and suggestions for the ultra-high-intensity redevelopment of the core area of hub stations by analyzing the aforementioned factors.

Keywords: core area, Japan, rail transit hub station, redevelopment, ultra-high intensity.
\end{abstract}

\section{INTRODUCTION}

Rail transit hub stations have important influence on urban industrial and spatial structures because of their inimitable reachable advantage. Thus, it becomes a significant accelerant of urban structure optimization for central and sub-central areas of the city. The redevelopment of land in rail transit hub stations and their core areas will improve the carrying capacity of urban traffic and peripheral land value by optimizing urban function configuration and improving public activity space. Such optimization will eventually lead to the sustainable diversification in city development.

Dutch researcher [1] Frank Bruinsma and Eric Pels have studied the influence of hub station redevelopment on urban vitality and evaluated the relationship between railway and urban vitality. Holgersen and Haarstad [2] have studied a case of urban redevelopment at King's Cross in London and they have presented three strategies for reinserting issues of class into planning theory and practice. Caballero and Tsukamoto [3] have studied the scale through the study of specific Tokyo districts and comparing and highlighting its differences with an urban configuration emerging in Tokyo through redevelopment projects. In general, their research has focused on the relationship between hub stations and urban redevelopment. Less attention has been paid to the definition of redevelopment intensity and the process of urban redevelopment, relevant laws, and policies. This study has carried out horizontal comparative analysis of several Japanese hub stations and compared the characteristics of these cases from four main aspects. In order to concretize this research further, we will analyze the planning process of urban development in Japan first.

The ultra-high-intensity redevelopment of the core areas of Japanese rail transit hub stations is concentrated in the densely populated capital of Tokyo and Keihanshin metropolitan areas. In the 1970s and 1980s, when the Japanese economy was deeply involved in globalization, many Japanese companies established headquarters in metropolises. This situation promoted the construction of offices and supporting facilities in urban centers [4]. Moreover, 
the boom in tourism brought a large number of foreign populations to central Japanese cities, such as Tokyo, Nagoya, and Osaka. As a result, the hub stations' traffic capacity needed to be expanded to meet the growing market demand [5]. This development also led to the urban redevelopment project centered on rail transit hub stations. Since then, the stereoscopic compound redevelopment model has gradually progressed.

Four stages can be concluded from the development of Japanese hub station areas [6] as follows:

- Early germination and development: The first stage occurred in the 1920 s to the 1950 s when the construction of rail traffic hubs was focused on government investment, whereas private capital participated in the commercial development of surrounding areas.

- Rapid development: The second stage was initiated in the 1950s. Due to World War II, the shortage of state-owned funds for the Japanese government resulted in a rapid development in the reconstruction of hubs and station core areas, which was invested by private developers. This stage includes three periods, that is, the construction period for public station buildings, the underground development period for hubs and the development period for station squares.

- Relatively slower period: The third stage was the slower development period for the rail traffic hubs during the Japanese bubble economy in late 1980s. During this stage, the development was minimal and mainly projected on single buildings rather than entire core areas.

- Redevelopment with ultra-high intensity: The fourth stage began at the end of the 20th century. To address the declining passenger flow in rail traffic and low consumption power around hub stations, the core areas of rail traffic hubs were redeveloped to optimize the allocation of land resources for upgrading space quality and maximize land potential and economic and social benefits. Consequently, the development intensity of the redevelopment was enhanced.

The Japanese government has placed increasing importance to the promotion of sustainable urban regeneration since the start of the 21 st century. In 2001, Japan officially proposed the urban regeneration policy, which was supported by the Urban Planning Law, Urban Redevelopment Law, and Special Legislation for City Regeneration [7]. The implementation framework of the motion is based on the establishment and emendation of specialized laws related to public housing, land acquisition, land planning, land renovation, decentralization, and non-government development. On the basis of the statistics from the Urban Redevelopment Law, over $60 \%$ urban redevelopment projects are associated with rail transit hub stations.

The Urban Planning Law revised in 2013 has identified a special urban regeneration district centered on rail transit hub stations [8]. It defines the floor area ratio (FAR), building area, building height, and building purpose. The special metropolis regeneration district includes five metropolis regeneration areas oriented by the Kanto region, namely, the northeast region; Kanto region; central region; Kinki region; and Chūgoku-Shikoku-Kyushu region (Table 1).

Strictly speaking, ultra-high-intensity redevelopment has yet to be clearly defined in the academic circle. FAR is a direct defining standard for measuring land development intensity. It can be used in zoning to limit urban density while directly limiting the core area of rail transit hub station's density and the number of people that the area can hold. Increasing the 
Table 1: Special urban regeneration district In Japan.

\begin{tabular}{ll}
\hline Geographical Region & Special Urban Regeneration District \\
\hline Northeast region & Sapporo station, Sendai Station \\
& Marunouchi, Oimachi, Yurakucho, Kyobashi, Ginza, \\
& Hamamatsu, Takeshiba, Nihonbashi, Toranomon, \\
Kanto region & Hibiya, Yaesu, Akihabara, Shinjuku station, Osaki \\
& Station, Shibuya Station, Shantou, Yokohama station \\
Central region & Gifu station, Hamamatsu station, Nagoya station \\
Kinki region & $\begin{array}{l}\text { Osaka station, Abeno station, Kanako Takatsuki, } \\
\text { Chūgoku, Shikoku \& }\end{array}$ \\
Kyushu region & Hiroshima station, Toshitsugu station, Kokura station \\
\hline
\end{tabular}

core area's FAR is equivalent to increasing the number of people that it can accommodate. The ratio of the total floor area is divided by the core area land (site) area [9]. Total floor area means the building's total floor space in a core area [10].

$$
\operatorname{FAR}(\%)=\frac{\text { Total floor area }}{\text { Site Plan }} \times 100 \%
$$

On the basis of the center area development intensity statistics from CBD with relatively high development intensity at home and abroad, the FAR of Manhattan, New York is 710\%; that of La Défense, Paris is 530\%; and that of the inner city, Westminster Abbey, as well as Docklands, London is 550\% [11]. The data show that the development FAR in rail transit impact area approaches or exceeds 10 . Thus, setting FAR to be greater or equal to $1000 \%$ as the standard of ultra-high-intensity development is appropriate. We take the rail transit hubs at Hongqiao, Kowloon, and Shibuya Stations, which are located in Minhang District in Shanghai, Yau Tsim Mong District in Hong Kong, and Shibuya District in Tokyo, as examples, with development FAR of the core area of $450 \%, 1240 \%$ and $1380 \%$, respectively (Table 2). The FAR in the core areas of Kowloon and Shibuya Stations exceed 1000\%. Thus, the redevelopment intensity of these two stations can be defined as ultra-high.

Table 2: Contrast Hongqiao station and Kowloon Station and Shibuya station.

\begin{tabular}{llll}
\hline Projects & Hongqiao Station & Kowloon Station & Shibuya Station \\
Location & $\begin{array}{l}\text { Minhang District, } \\
\text { Shanghai }\end{array}$ & Yau Tsim Mong District, & Shibuya District, \\
& Hong Kong & Tokyo. \\
Construction time & 2009 & 1996 & 2027 \\
Site Area & $1,430,000 \mathrm{~m}^{2}$ & $135,417 \mathrm{~m}^{2}$ & $42,700 \mathrm{~m}^{2}$ \\
Total Area & $1,700,000 \mathrm{~m}^{2}$ & $1,679,552 \mathrm{~m}^{2}$ & $693,900 \mathrm{~m}^{2}$ \\
FAR & $450 \%$ & $1240 \%$ & $1380 \%$ \\
\hline
\end{tabular}




\section{ANALYSIS OF TYPES OF REDEVELOPMENT}

The redevelopment of Japanese rail traffic hubs is often complicated, mostly located in central or sub-central areas of the city, and restricted by all sorts of conditions. Moreover, redevelopment is usually accompanied by functional adjustments. In view of functional characteristics, the ultra-high-intensity redevelopment of Japanese rail traffic hub areas can be classified into three types: functional replacement, expansion, and reorganization.

\subsection{Functional replacement redevelopment}

This type of redevelopment can improve land use efficiency and value by replacing the function of the original land. Typical examples are the redevelopment of Yaesu Entrance in Tokyo Station and that of Shibuya Station.

Tokyo Station, which is located in Chiyoda, Tōkyō-to, Japan, is an important city and transportation hub. In addition to seven subway lines, it serves five Shinkansen railway stations. With an average daily passenger flow of 1.14 million, it is a crucial urban traffic hub in Tokyo. The redevelopment project of the Tokyo Station aims to renovate the front square of the Marunouchi Station and redeveloping the Yaesu Entrance [12]. Before the redevelopment, the Yaesu Entrance was dominated by densely regulated middle- to low-rise residences with few large retail facilities and office facilities. The redeveloped Yaesu Entrance replaced the original residences with commercial-office-oriented urban complex. Given the functional replacement of nearby areas within $200 \mathrm{~m}$ around the entrance, office and commercial buildings with high land value were constructed to achieve efficient land utilization. Finally, the Tokyo Station has become a stereo-integrated station that has a core impact with functional domain above ground, on ground, and underground (Fig. 1).

Shibuya Station, which is located in Tokyo's vice-center Shibuya, is a large hub station that has eight rail transit lines converging over three million daily passengers. After nearly 100 years of expansion, Shibuya Station has encountered many problems, including complicated transfer routes, narrow front square public space, seriously deteriorating municipal facilities, and crowded traffic. The redevelopment replaced single housing with collective housing and changed commercial-office, entertainment and mixed commercial-residential facilities into commercial, office, entertainment and cultural facilities. In addition, areas within four blocks of the Shibuya Station were redeveloped, including the Station Street, South Street of Shibuya Station, Dogenzaka Street, and Sakuragaoka Street. Thereafter, the first complex of Shibuya, which is called Hikarie, was opened in 2012 [13]. The opening of Hikarie marked the key stage of the redevelopment of the Shibuya Station complex. Simultaneous redevelopment

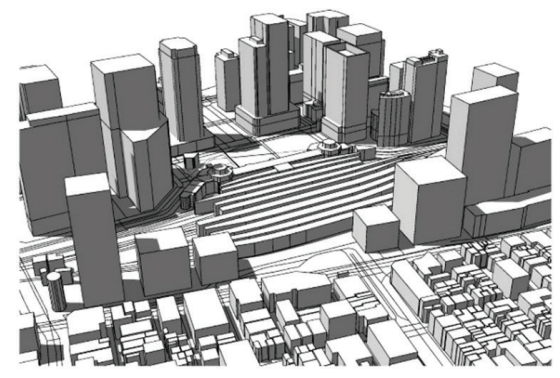

Before Redevelopment

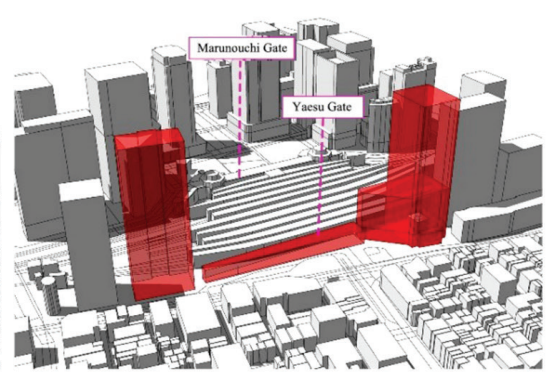

After Redevelopment

Figure 1: Redevelopment of Tokyo station. 


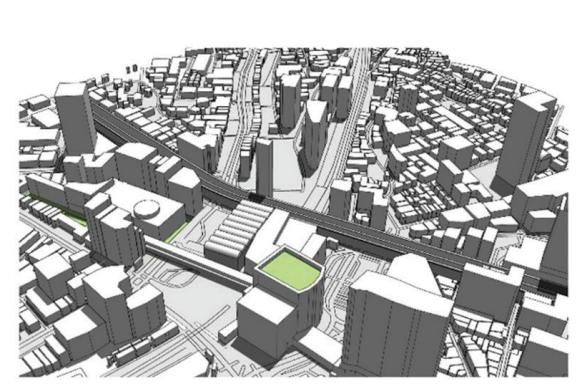

Before Redevelopment

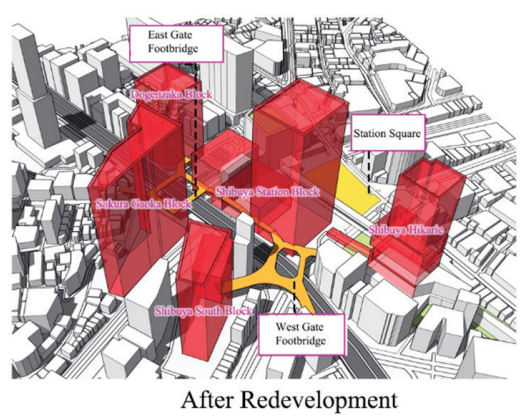

After Redevelopment

Figure: 2 Redevelopment of Shibuya station.

included the shifting of the original station platform, the renovation of front square, and the expansion of the surrounding complex. The value of urban land was considerably increased, and the development of station peripheral was empowered while realizing the integration of urban infrastructure and urban functions, such as rail transit (Fig. 2).

\subsection{Functional expansion redevelopment}

This type of redevelopment takes function supplements as primary. It increases the diversity of the hub station core area through high-intensity development targeted on the original land and supplement of missing function in case that the overall functional structure is relatively complete and the original function is not largely replaced. The redevelopment of the Shinjuku Station's New South Entrance and the joint redevelopment of Ikebukuro and Higashi Ikebukuro Stations are typical examples.

Shinjuku Station, which is located in Shinjuku, Tokyo, owns the world's largest average daily passenger flow among comprehensive transport hubs. It has 11 rail lines; 41 urban lines; 10 high-speed lines; and traffic facilities, such as high-speed bus with 3.64 million daily average passengers. On the basis of previous high-intensity development of underground space and station core area, Shinjuku Station redeveloped its New South Entrance. The redevelopment added new entrances and a station complex that covers an area of 1.47 ha. The complex includes a multitier station building and a high-rise complex. The redevelopment project contains high- and low-rise sections, of which high-rise buildings are built $170 \mathrm{~m}$ from the ground floor to the 33rd floor. In this section, the 6th-33rd floors are used as office zones. By contrast, the low-rise section is used for commercial and station facilities, among which the ticket entrance is on the 2nd floor, the transfer center for taxis and minibuses is on the 3rd floor, and the transfer center for express bus is on the 4th floor (Fig. 3).

Ikebukuro Station, which is located in Toshima District, Northwestern Tokyo, is a comprehensive urban sub-center that integrates business, culture, education, and transportation with 2.58 million daily average passenger flow. The development of the entire sub-center blocks around the Ikebukuro Station was realized through the expansion of the East and West Entrances, as well as the joint development of Ikebukuro and Higashi-Ikebukuro Station. In the Higashi-Ikebukuro Station redevelopment project, the Sunshine City Commercial Complex plays the most important role. It contains four buildings: a 60 -floor super high-rise business office building, a major hotel building, an import shop building, 


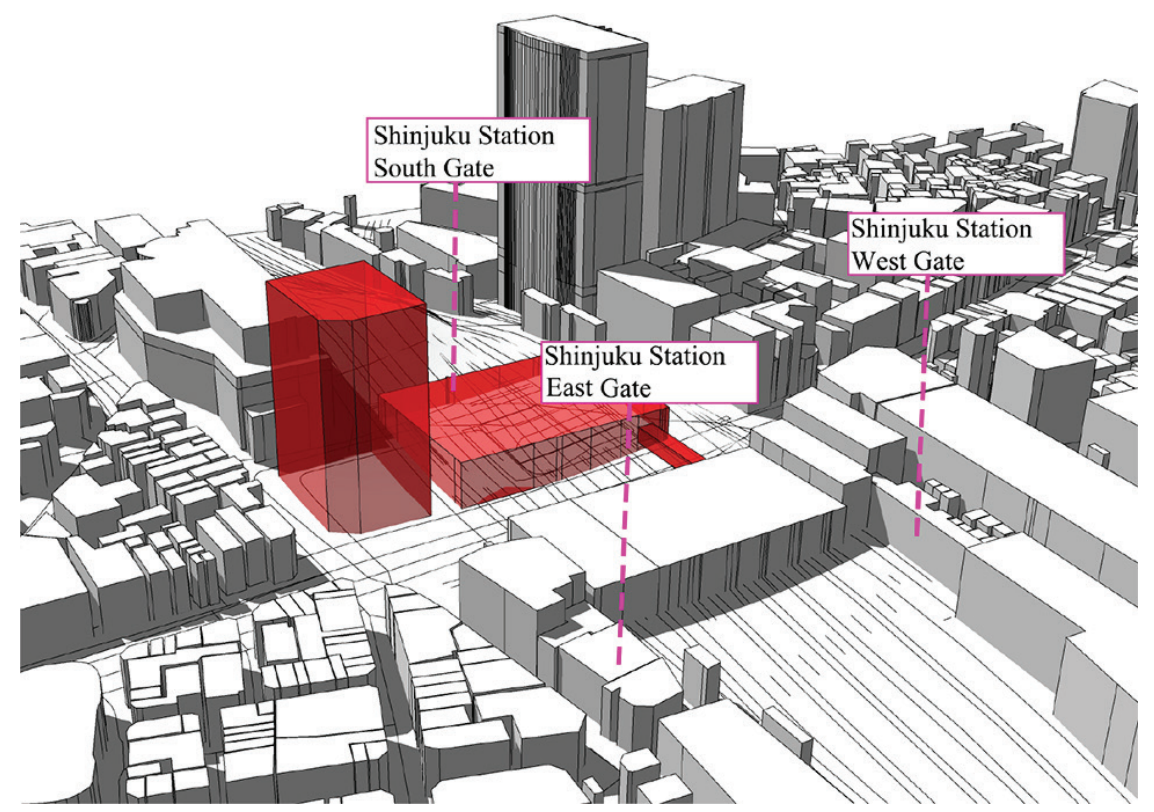

Figure: 3 Redevelopment of Shinjuku station.

and a cultural hall building. The Sunshine City lightens the traffic congestion in the Ikebukuro Station and organically decomposes the pedestrian traffic flow on the basis of the joint redevelopment of Ikebukuro and Higashi-Ikebukuro Stations. With this project, a unified and orderly block between the two stations is established and the sub-center of Ikebukuro is developed (Fig. 4).

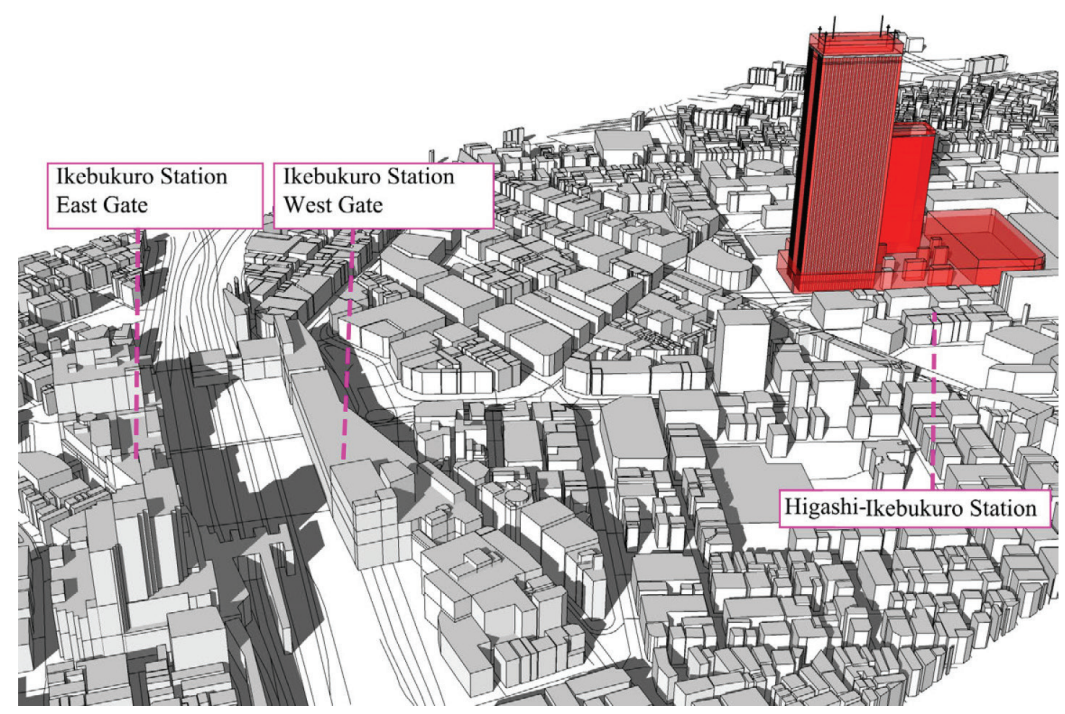

Figure: 4 Redevelopment of Ikebukuro station. 


\subsection{Functional reorganization redevelopment}

This type of redevelopment is designed to update the surrounding land of the traffic hub through re-planning and construction of the station core area after the large-scale reorganization of the original function of surrounding areas. Functional replacement and augmentation of partial region are also involved. The redevelopment of Shinbashi-Shiodome Station and the north district of Osaka Station are typical examples functional reorganization redevelopment.

Shinbashi-Shiodome Station is located in 1 Chome, Shinbashi, Minato, Tokyo with 0.77 million daily average passengers. The redevelopment project of Shiodome Station covers an area of 31 ha. The land was originally used as Shiodome freight station, which was officially abolished in 1986. After over 20 years of planning and construction, buildings retained around Shiodome Station are mostly large-scale integrated commercial buildings that function as apartments, offices, and hotels. The massive reorganizational redevelopment included 11 streets in five blocks with a total construction area of 1.68 million $\mathrm{m}^{2}$. A total of 13 super highrise buildings have been built, which are connected by skywalks, underground plazas, and passages. The redevelopment achieved remarkable results, which not only revitalized urban regeneration but also created dimensional, green, and sustainable hub station areas (Fig. 5).

Osaka Station, which is located in 3 Chome, Umeda, Osaka Prefecture, is operated and managed by JR West Japan with 2.5 million daily average passengers. Similar to ShinbashiShiodome Station, the redevelopment of the north area of Osaka Station was reorganized by the abandoned Umeda freight station. The redevelopment included two phases. First, a station complex was constructed in 2011, which covers an area of approximately 7 ha and includes three composite office buildings, a common commercial podium, and facilities, such as intercontinental hotels and Umekita Plaza. In this phase, the entire area is divided into north and south by axe, thereby creating a space filled with water and plants through the combination of

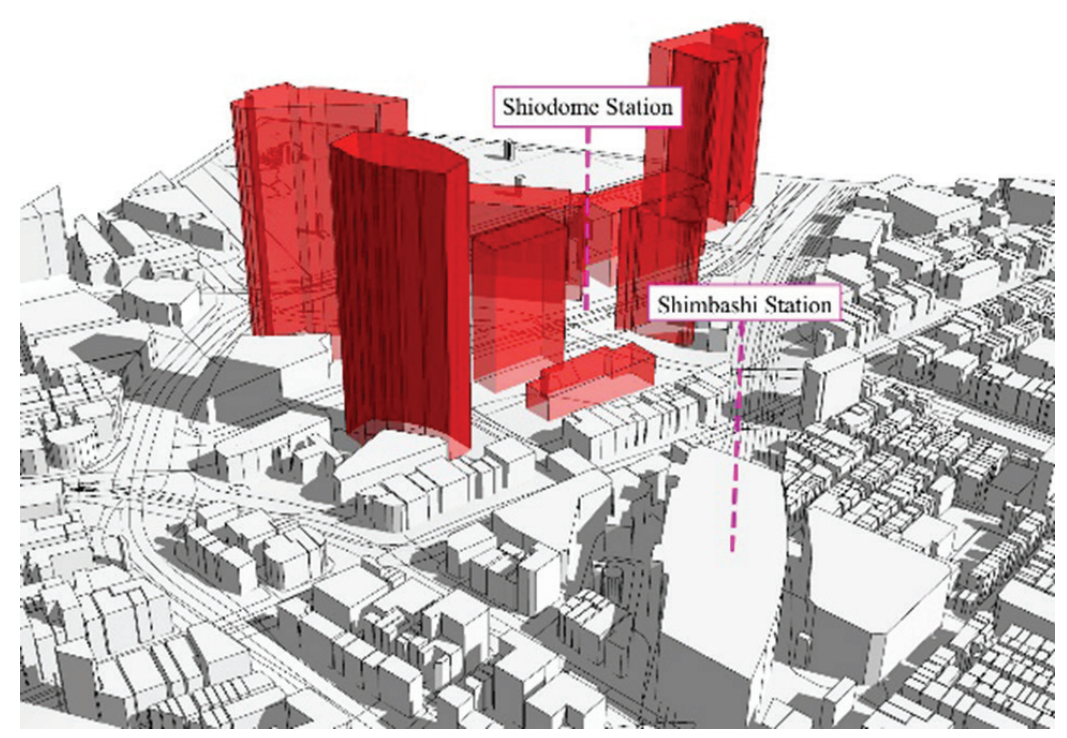

Figure: 5 Redevelopment of Shiodome station. 


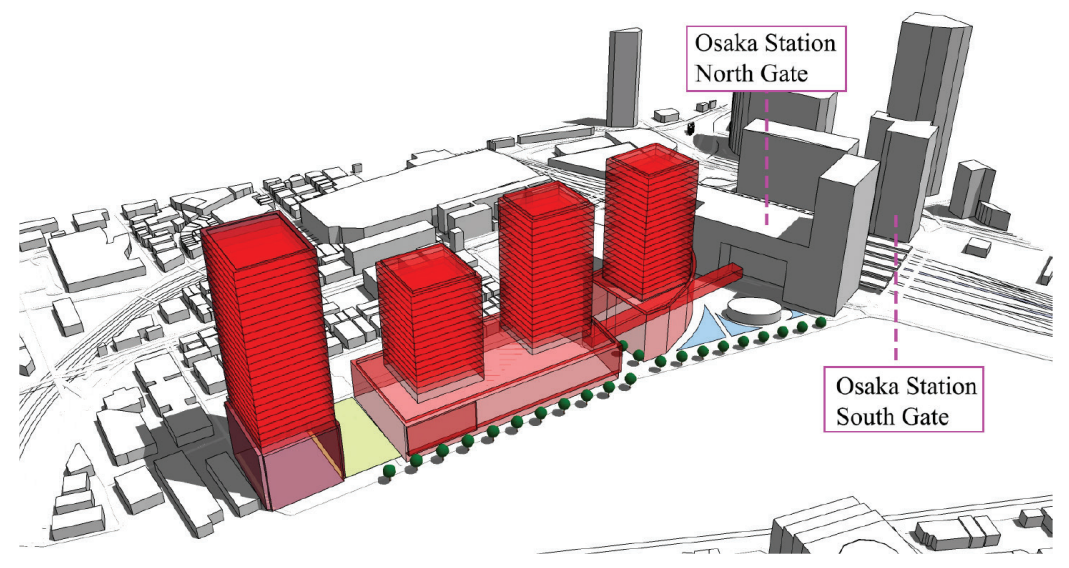

Figure: 6 Redevelopment of North area of Osaka station.

wide walkways and buildings, as well as the decoration of facilities, such as Umekita Plaza. The second phase roughly covers an area of 17 ha and intends to build a new site (Fig. 6).

\section{STRATEGY ANALYSIS}

\subsection{FAR promotion based on space optimization}

The spatial location and traffic accessibility of rail traffic hub core area possess obvious advantages compared with other urban areas. Therefore, the value of land is self-evident. The huge redevelopment investment calls for high earnings [14]. Thus, increasing development intensity on the basis of high-intensity development, which is close to saturation, is the key to returning the investment. The necessary measure of increasing development intensity is promoting FAR. Floor building density can be reduced, and FAR can be increased by reorganizing original transportation facilities and building complexes, especially applying multilevel stereo space medium and tremendous gray space. In this case, urban space can be optimized, and the quality of the environment can be improved. The development intensity changes in Osaka and Shibuya Stations are shown in Table 3.

The redevelopment project of Osaka Station's North Entrance is divided into Phases I and II. The first phase is for the development of the North Square Complex. The FAR was increased from $700 \%$ to $1300 \%$ after the redevelopment, and the redevelopment of Shibuya Station was based on that of the station block [15]. The reconstructed JR Shibuya Station Building is designed to be an upper cover compound complex. More specifically, the FAR for the redevelopment of the four major redevelopment blocks was raised to more than $1000 \%$ with the FAR of the station block reaching $1560 \%$. The increase in FAR also led to high-intensity land use within $500 \mathrm{~m}$ of the hub station, which successfully established a composite block [16].

\subsection{Diversified function layout}

The accessibility of rail traffic hub contributes to the circle function distribution of the core area. The commercial and related business facilities in the station are usually developed the 
Table 3: Contrast of development intensity of Osaka station and Shibuya station.

\begin{tabular}{|c|c|c|c|c|c|c|}
\hline \multirow[b]{2}{*}{ Station } & \multirow{2}{*}{$\begin{array}{c}\text { Subway } \\
\text { Line }\end{array}$} & \multirow{2}{*}{$\begin{array}{c}\text { Number of } \\
\text { passengers } \\
\text { per day }\end{array}$} & \multicolumn{3}{|c|}{ The Change of FAR } & \multirow{2}{*}{$\begin{array}{c}\text { Site Area of } \\
\text { Redevelopmen }\end{array}$} \\
\hline & & & Project name & Before & After & \\
\hline $\begin{array}{l}\text { Osaka } \\
\text { station }\end{array}$ & 8 & $2,500,000$ & $\begin{array}{c}\text { Grand Front } \\
\text { Osaka }\end{array}$ & $700 \%$ & $1300 \%$ & $\begin{array}{l}\text { Phase I: } 7 \text { ha } \\
\text { Phase II: } 17 \text { ha }\end{array}$ \\
\hline $\begin{array}{l}\text { Shibuya } \\
\text { station }\end{array}$ & 8 & $3,230,000$ & $\begin{array}{c}\text { Station Block } \\
\text { South Block } \\
\text { Dogenzaka Block } \\
\text { Sakuragaoka } \\
\text { Block }\end{array}$ & $\begin{array}{l}1000 \% \\
710 \% \\
840 \% \\
560 \%\end{array}$ & $\begin{array}{l}1560 \% \\
1350 \% \\
1400 \% \\
1230 \%\end{array}$ & $\begin{array}{l}\text { 4.3ha } \\
1.0 \mathrm{ha} \\
0.6 \mathrm{ha} \\
2.6 \mathrm{ha}\end{array}$ \\
\hline
\end{tabular}

earliest. Then, on the basis of the promotion of the station commercial value, businesses outside the station are constructed by means of connection to the station building [17]. After the near-circle development, drawbacks gradually emerge due to a single business pattern as consumer behavior continues to escalate; these drawbacks include uneven business flow, monotonous business model, and unreasonable model distribution. Moreover, highly abundant commerce will hinder traffic accessibility, thereby causing a decline in constant business dynamism and pedestrian retention. In this situation, consumer desire will be reduced significantly [18]. Therefore, a targeted implementation scheme is proposed (Fig. 7). First, the redevelopment should expand near-circle function, foster distinctive business, construct more public space to promote the diversification of station core area function, and enhance core area spatial vitality. Second, high development intensity of the core area is inevitable due to the demand of increased earnings, Moreover, reasonable FAR distribution is the key to avoiding traffic congestion and low urban space quality caused by excessive development intensity [19].

The reconstruction of 0-200 m pedestrian distance area of the station focuses on service facilities, such as station front square, in which the FAR generally remains unchanged or even decreases. The 200-300 m pedestrian distance area of the station has the highest development value and is the center of ultra-high-intensity redevelopment. It is efficient in avoiding the hedging of pedestrian flow and in attracting and changing pedestrian flow into commercial flow. Therefore, entertainment and culture functions are appropriately increased along with commercial and office construction. As the edge of core area, the 300-500 m pedestrian

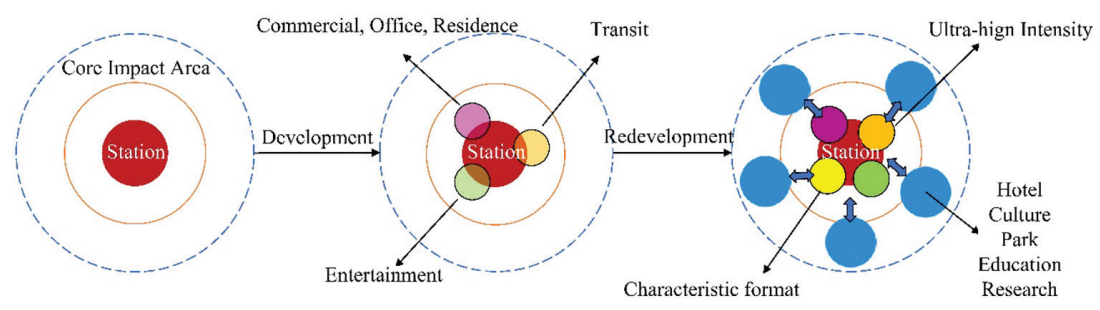

Figure 7: Redevelopment of urban function in Japanese rail transit hub station. 
Table 4: Contrast before and after redevelopment of area within $0-500 \mathrm{~m}$ range of the station.

\begin{tabular}{|c|c|c|c|c|}
\hline \multirow{2}{*}{$\begin{array}{l}\text { Station } \\
\text { range }\end{array}$} & \multicolumn{2}{|c|}{ Before redevelopment } & \multicolumn{2}{|c|}{ After redevelopment } \\
\hline & Functional & FAR & Functional & FAR \\
\hline $\begin{array}{l}\text { 0-200 m } \\
\text { Area }\end{array}$ & $\begin{array}{c}\text { Station and } \\
\text { ancillary } \\
\text { facilities, } \\
\text { mixed land of } \\
\text { commercial and } \\
\text { office }\end{array}$ & $500 \%-800 \%$ & $\begin{array}{l}\text { Station and Square, } \\
\text { connection facilities, } \\
\text { public space and } \\
\text { mixed land of } \\
\text { commercial and } \\
\text { office }\end{array}$ & $1000 \%$ \\
\hline $\begin{array}{l}200 \mathrm{~m}-300 \mathrm{~m} \\
\text { Area }\end{array}$ & $\begin{array}{c}\text { Culture and } \\
\text { entertainment } \\
\text { industry, a few } \\
\text { offices }\end{array}$ & $500 \%-1000 \%$ & $\begin{array}{c}\text { Culture and } \\
\text { entertainment } \\
\text { industry, high } \\
\text { density mixed land } \\
\text { of commercial and } \\
\text { office }\end{array}$ & $800 \%-1500 \%$ \\
\hline $\begin{array}{l}300 \mathrm{~m}-500 \mathrm{~m} \\
\text { Area }\end{array}$ & $\begin{array}{l}\text { entertainment } \\
\text { industry, a few } \\
\text { high density } \\
\text { commercial } \\
\text { residences }\end{array}$ & $800 \%-1200 \%$ & $\begin{array}{l}\text { Few culture and } \\
\text { entertainment } \\
\text { industry, high } \\
\text { density office } \\
\text { and commercial } \\
\text { residences }\end{array}$ & $600 \%-1000 \%$ \\
\hline
\end{tabular}

distance area should appropriately supplement residential, cultural, and entertainment functions to avoid tidal phenomena in the station core area. It should also add multilevel pedestrian connection facilities to improve walking efficiency and promote land value [20]. The functional layout after the redevelopment is shown in Table 4.

\subsection{Multilevel pedestrian system}

Rational organization and optimization of pedestrian system is a key point to improve the development value by organically evacuating rail transit passenger flow and realizing the transformation between traffic and commercial flows. On the basis of action form, it can be categorized as follows [21]:

- Main line: The main line is the fiber element that constructs the pedestrian network of the hub core area, which rationally distributes traffic passengers in space and time.

- Node: The node is a fiber intersection of the pedestrian network and is the function transition space of various core areas, which is the kernel of organic evacuation and an important object that reflects urban place spirit.

- Traffic hub: The traffic hub is the key to multilevel and stereo pedestrian systems, which enable the traffic flow to intertwine at different times and spaces.

Figure 8 shows the characteristics of changes before and after the redevelopment of a pedestrian system. 

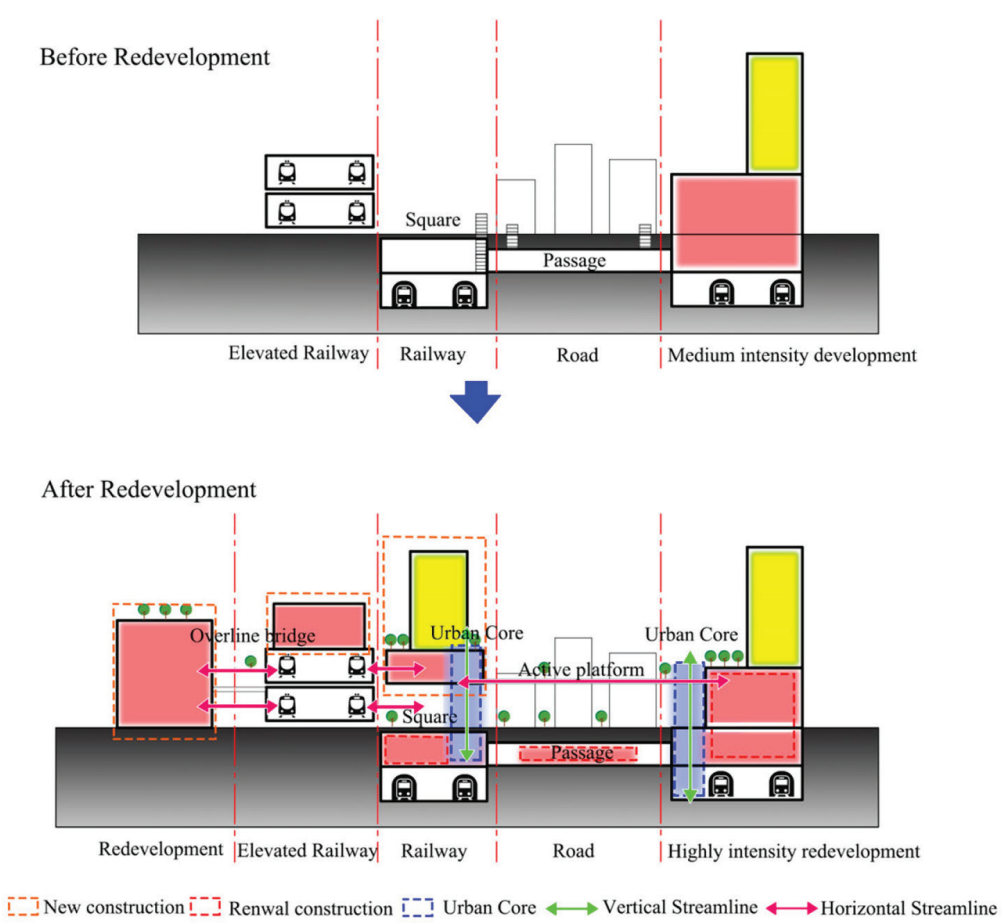

Figure 8: Multi-layer walking network.

- Multilevel pedestrian connection facilities must be constructed to connect other complexes for enhancing the utilization efficiency of surrounding areas.

- Previous stairs and elevators must be supplemented or replaced with a stereo traffic hub. At the same time, pedestrian connection facilities are used to contact different stereo traffic hubs.

- Commercial development must be conducted with reasonable intensity inside underground passages.

- Public activity places should be converted or implanted into a multidimensional space, which includes traffic square, pedestrian connection facilities, surrounding pedestrian walkway, and roof platforms of the rail transit complex.

In the redevelopment of Shibuya Station, a multilevel stereo pedestrian transportation system was established by building a stereo front square. This front square connects the hub station, thereby reconstructing and optimizing various public facilities of the pedestrian roads, setting up hub stations, as well as vertical public transportation "urban core" that connects the complex. The vertical traffic hub links the underground (underpass and underground facilities), the ground (station square and pedestrian streets), and the air (walking bridges and pedestrian platforms), thereby forming a multidimensional pedestrian system that effectively directs people by multilevel pedestrian facilities to cities [23]. By doing so, the connection between the station and urban functional space is effectively improved. 


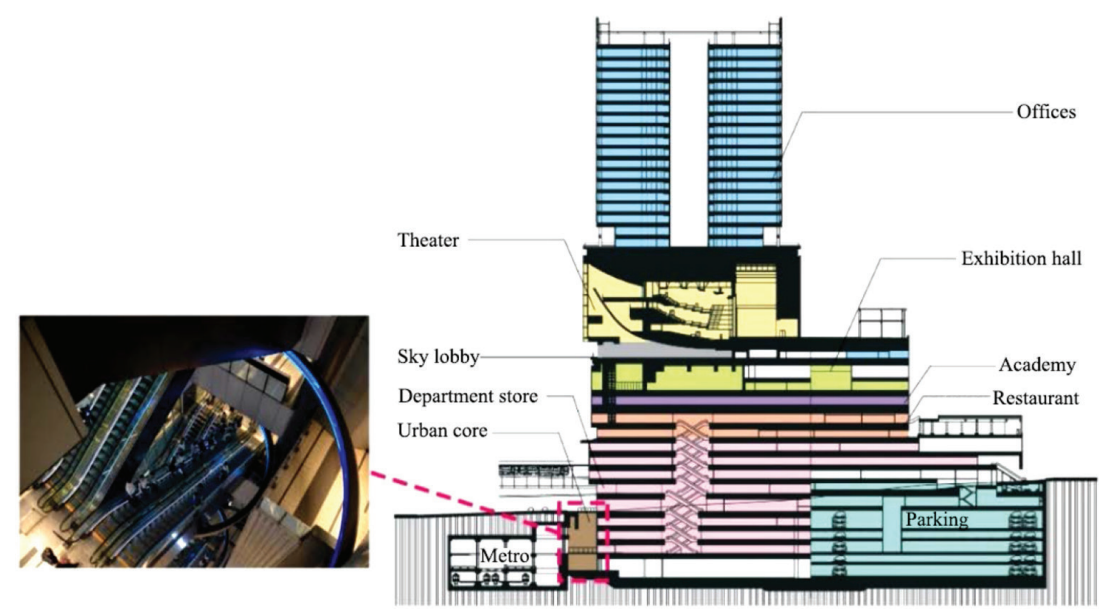

Figure 9: Urban core of Hikarie, Shibuya station.

The Hikarie complex (Fig. 9) is connected to the Shibuya Station block through the second-floor passage with a city core established inside. Moreover, the complex is connected with the underground, ground, and air by stereo pedestrian passages. Urban traffic diversion is affected by the width, distance, and transit time of the connecting facilities. Thus, reasonable space between the traffic load center and the complex achieves stable walking experience. Furthermore, the stereo traffic core is located inside the rail transit complex and is joined to the commercial entrance of each floor. Thus, the commercial consumption possibility of the rail transit complex and the potential commercial consumption power of 200-500 m area near the station are effectively facilitated, which results in high economic benefits for the commercial complex.

\subsection{Multi landscape space}

Landscape space enables people from different social levels and value systems to communicate and coexist with one another, such that their diverse behaviors and activity needs can be satisfied. As the key to creating the character of the station, high-quality landscape space increases the land value of station core areas.

Taking the north complex of Osaka Station as an example (Fig. 10), the landscape space in North Osaka Station follows the multilevel and stereo system dominated by aerial landscape space. The Umekita Plaza, South and North Terrance Garden, North Garden, and pedestrian walkway are all included [24]. Furthermore, the landscape planting of North Osaka Station successfully connects the entire northern part of Osaka Station [25]. Therefore, the landscape space acts as the buffer space of each functional block, and the tandem of the landscape space greatly enhances the integrity and accessibility of the Osaka Station and its core area.

\section{CONCLUSION}

Urbanization continues to accelerate, and the changes in people's lifestyles and consumption patterns will drive diversified and composite development of urban rail transit hub. Simultaneously, rail transit hub stations are sure to be free from the limitation of traffic 


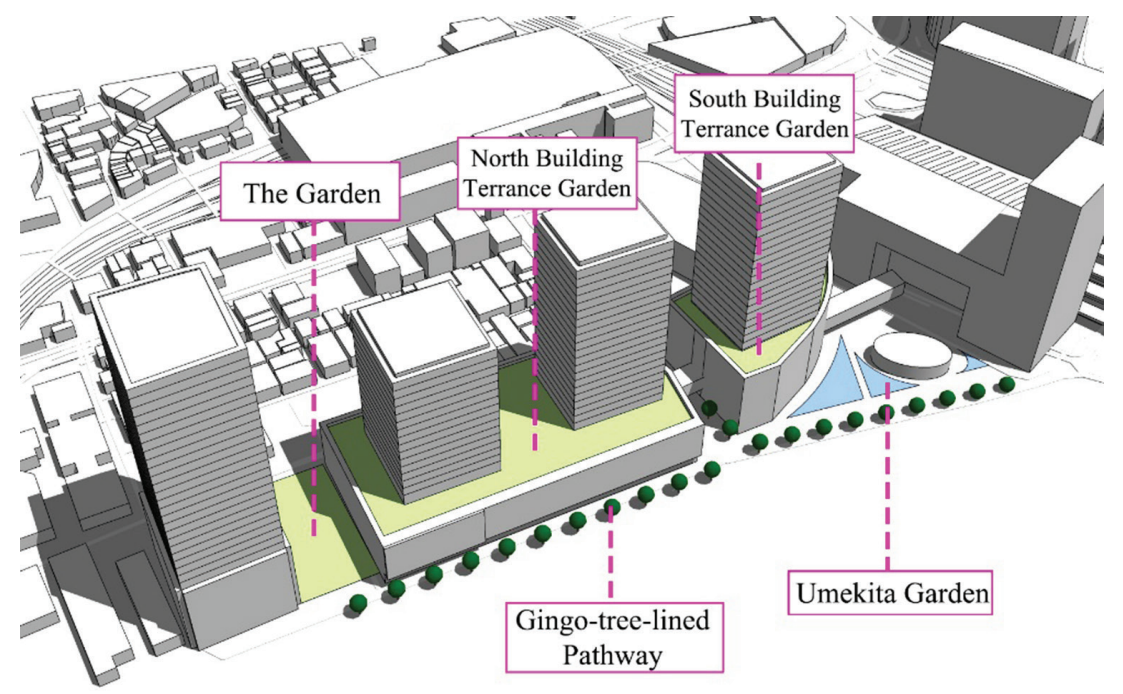

Figure: 10 The landscape space of the Grand-Front Osaka.

function. Japan's more than one century's practice can provide references on the planning, design, construction, management, and operation of the redevelopment of rail traffic hubs. Generally, urban redevelopment aims to provide additional spaces for people and improve urban compactness without sacrificing urban public space. Such purpose needs the consideration of many factors. In comparison with other research, this study synthesizes influencing factors, such as FAR promotion, functional layout, pedestrian system, and landscape space.

By comparing different Japanese cases, we can gain useful insights on the manner in which the core area of rail transit hub stations is optimized from the planning and design level. The conclusions drawn are as follows.

- A series of redevelopment legal systems and local regulations are established. The government encourages research institutions, developers, and the public to participate in redevelopment projects and optimize the planning scheme in a timely manner during the phased development.

- The redevelopment projects follow the principle of overall urban planning to improve traffic efficiency and optimize urban functions for the improvement of the overall vitality of the city.

- Redevelopment has raised the intensity of stations' $500 \mathrm{~m}$ radius to over $1000 \%$ of FAR, of which the FAR of $200-300 \mathrm{~m}$ is the highest and $0-100 \mathrm{~m}$ is the lowest. Multi-composite blocks are formed by optimizing function after redevelopment. Optimized multilevel traffic walking system in horizontal and vertical directions increases the transfer of multiple modes of transportation, as well as increases urban greening rate and optimizes three-dimensional space landscape.

\section{ACKNOWLEDGEMENTS}

The research is supported by the National Natural Science Foundation of China (Grant No. 51478198), Promotion Program of Young and Middle-aged Teacher in Science and Technology Research of Huaqiao University, China (Grant No. ZPN-YX306). 


\section{REFERENCES}

[1] Holgersen, S. \& Haarstad. H., Class, community and communicative planning: urban redevelopment at king's cross, London. Antipode, 41(2), pp. 348-370, 2009. https://doi. org/10.1111/j.1467-8330.2009.00676.x

[2] Bruinsma, F., Pels, E., Priemus, H., Rietveld, P. \& Van Wee, B., Railway Development: Impacts on Urban Dynamics, Physica, 2008.

[3] Caballero, J.A. \& Tsukamoto, Y., Tokyo public space networks at the intersection of the commercial and the domestic realms study on transit urban centers. Journal of Asian Architecture and Building Engineering, 8(2), pp. 461-468, November 2009.https://doi. org/10.3130/jaabe.8.461

[4] Morita, Y., Morichi, S. \& Ito, M., A study on coordination between urban development and station capacity. Case Studies on Transport Policy, 3(1), pp. 78-91, 2015. https:// doi.org/10.1016/j.cstp.2014.04.003

[5] Shelton, B., Learning from the Japanese City: Looking East in Urban Design, London; New York, NY: Routledge, 2012.

[6] Nikken Sekkei, K.K., Integrated Station-City Development Research Association, Integrated Station-City Development, Beijing: China Architecture \& Building Press, 2014.

[7] Zacharias, J., Zhang, T. \& Nakajima, N., Tokyo Station City: The railway station as urban place. Urban Design International, 16(4), pp. 242-251, December 2011. https:// doi.org/10.1057/udi.2011.15

[8] Holmgren, S. \& Svensson, O., Urban architecture in urban renewal-in dialogue between professionals and residents. Urban Design International, 6(1), pp. 2-14, 2001. https://doi.org/10.1057/palgrave.udi.9000034

[9] Birch, E.L., The Urban and Regional Planning Reader, Routledge, 2009.

[10] Barr, J. \& Cohen, J.P., The floor area ratio gradient: New York City, 1890-2009. Regional Science \& Urban Economics, 48, pp. 110-119, 2014. https://doi.org/10.1016/j.regsciurbeco.2014.03.004

[11] Crager, E. \& Crossney. K., A Comparison Study of Urban Redevelopment Strategies in the Philadelphia metropolitan Area, 2012.

[12] Kashima, K., Station Regeneration, Tokyo: Kajima Press, 2010.

[13] Yamamoto, S., Takehara, J. \& Fujihashi, T., Redevelopment of Shibuya - explore the secrets of Shibuya Hikarie. Journal of the Institute of Electrical Engineers of Japan, 314(8), pp. 568-571, 2014. https://doi.org/10.1541/ieejjournal.134.568

[14] Carmona, M. \& Magalhaes, C.D. \& Edwards, M., Stakeholder views on value and urban design. Journal of Urban Design, 7(2), pp. 145-169, 2002. https://doi. org/10.1080/1357480022000012212

[15] Zhang, X., Guiding effect of urban regeneration policy on comprehensive urban development. Architecture Technique, pp. 20-25, 2015.

[16] Yang, X., Official launch of the large-scale redevelopment project on surrounding area of japanese premier traffic hub Shibuya station. Time Architecture, pp. 77-79, 2009.

[17] Taniguchi, H., Urban Redevelopment, Beijing: China Architecture \& Building Press, 2003.

[18] Okada, T., Arita, T. \& Omura, K., Study on influences on functions of the central business area of Tokyo from large scale urban redevelopment projects. Journal of the City Planning Institute of Japan, 43(3), pp. 469-474, 2008.

[19] Chena, H., Ookaa, R., Iwamura, K., Huang, H., Yoshizawa, N., Miisho, K. ... \& Tanaka, S., Study on sustainable redevelopment of a densely built-up area in Tokyo by introducing a distributed local energy supply system. Energy and Buildings, 40(5), pp. 782-792, 2008. https://doi.org/10.1016/j.enbuild.2007.05.012 
[20] Morita, K.I., Evaluation of floor area ratio in redevelopment district plan, Tokyo. Journal of the City Planning Institute of Japan, (35), pp. 367-372, 2000.

[21] Ooe Kouhei. Study on Soft-Contribution Facility in the Special District for Urban Regeneration in the Tokyo. Part 2: Actual Operation of Regional Exchange Facility. Summaries of Architectural Institute of Japan, pp. 557-558, 2014.

[22] Corbett, M.J., Xie, F. \& Levinson, D., Evolution of the second-story city: The Minneapolis skyway system. Environment and Planning B: Planning and Design, 36(4), pp. 711-724, 2009. https://doi.org/10.1068/b34066

[23] Otsuka, N., Dixon, T. \& Abe, H., Stock measurement and regeneration policy approaches to 'hardcore' brownfield sites: England and Japan compared. Land Use Policy, 33, pp. 36-41, 2013. https://doi.org/10.1016/j.landusepol.2012.12.002

[24] Yang, C. \& Yao, M., The renewal history of Osaka station and enlightenment. Chinese \& Overseas Architecture, pp. 27-30, 2017.

[25] Kitaumeda-osaka official organization. www.Kitaumeda-osaka.jp 